\title{
ANALISIS Produktivitas Pabrik Spiritus Menggunakan Fungsi Produksi Cobb-Douglas (Studi Kasus Di PT. XYZ Yogyakarta)
}

\author{
Jono \\ Jurusan Teknik Industri \\ Universitas Widya Mataram Yogyakarta \\ Yonuwm@yahoo.co.id
}

\begin{abstract}
Abstrak
Produktivitas merupakan suatu ukuran penilaian yang digunakan perusahaan untuk mengetahui kinerja perusahaan dalam melakukan proses produksi. Pengukuran produktivitas perlu dilakukan secara teratur dan terus menerus agar dapat diketahui efektivitas dan efisiensi penggunaan sumber daya perusahaan dalam menghasilkan output yang dikehendaki. PT XYZ merupakan perusahan yang memproduksi spirtus dan alkohol. Dalam produksinya mengalami pasang surut setiap tahun. Pengukuran produktivitas dapat dilakukan dengan menggunakan fungsi Cobb-Douglas yang mampu menggambarkan keadaan skala hasil (return to scale). Penelitian ini bertujuan untuk mengetahui kondisi produktivitas Pabrik Spiritus PT XYZdengan menggunakan fungsi produksi Cobb-Douglas, dan mengetahui Indeks Produktivitas yang dicapai Pabrik spiritus PT XYZ. Pengukuran produktivitas di Pabrik Spiritus PT XYZ dengan Fungsi Cobb-Douglas menggunakan dasar perhitungan input berupa tetes tebu dan output berupa alkohol. Hasil penelitian menyimpulkan bahwa Produktivitas Pabrik Spiritus PT XYZ Yogyakarta menurut fungsi produksi Cobb-Douglasmengindikasikan bercirikan skala hasil menurun (decreasing returns to scale), dengan elastisitas output sebesar 0,899. Indeks produktivitas Pabrik Spiritus PT XYZ rata-rata adalah sebesar 382 atau 27,2\% diatas produktivitas standar dan meningkat rata-rata 5,4\% tiap bulan. Disarankan sebaiknya Perusahaan bisa menggunakan fungsi produksi Cobb-Douglas dalam melakukan pengukuran produktivitas perusahaan, selain menggunakan metode pengukuran yang selama ini sudah dipakai untuk membuat kebijaksanaan demi peningkatan produktivitas perusahaan di masa mendatang. Peningkatan produktivitas Pabrik Spiritus PT XYZ masih bisa ditingkatkan karena elastisitasnya berada pada daerah rasional. Salah satu cara yang bisa dilakukan adalah dengan peningkatan efisiensi tenaga kerja baik jumlah maupun kualitasnya.
\end{abstract}

Kata kunci : Analisis Produktivitas, Cobb-Douglas.

\section{PENDAhULUAN}

Dalam suatu perusahaan, proses industri merupakan faktor utama sehingga harus dilakukan perbaikan secara terus menerus. Mulai dari adanya ide untuk menghasilkan suatu produk, pengadaan bahan baku, proses produksi,peningkatan efisiensi, sampai pada pendistribusian produk kepada konsumen. Proses industri yang baik, teratur dan sistematis akan menghasilkan output yang mempunyai efisiensi dan efektivitas yang terus meningkat, sehingga biaya produksi dapat dikurangi dan keuntungan perusahaan mengalami peningkatan. Produktivitas bertujuan menghasilkan lebih banyak dan jasa dengan menggunakan sumber daya seminimal mungkin. Oleh karena itu, produktivitas itu penting diperhatikan oleh perusahaan karena dapat menggambarkan sejauh mana tingkat perkembangan perusahaan.

Produktivitas merupakan suatu ukuran penilaian yang digunakan perusahaan untuk mengetahui kinerja perusahaan dalam melakukan proses produksi. Pengukuran produktivitas perlu dilakukan secara teratur dan terus menerus agar dapat diketahui efektivitas dan efisiensi penggunaan sumber daya perusahaan dalam menghasilkan output yang dikehendaki. Peningkatan produktivitas menandakan kemajuan perusahaan dan demikian sebaliknya. Peningkatan produktivitas juga berarti peningkatan kesejahteraan dan kualitas perusahaan yang akan sangat berpengaruh terhadap kemampuan perusahaan memenuhi keinginan konsumen.

Pengukuran produktivitas yang selama ini dilakukan di Pabrik Spiritus adalah dengan metode konvensional pabrik yaitu dengan membandingkan jumlah output (alkohol dalam satuan liter) dengan jumlah input (pemakaian bahan baku berupa tetes tebu dalam satuan $\mathrm{Kg}$ ) 
Untuk mengetahui kondisi produktivitas bila dilakukan perhitungan menggunakan metode fungsi produksi Cobb-Douglas

Fungsi Produksi Cobb-Douglas dipilih karena Fungsi produksi Cobb-Douglas mampu menggambarkan keadaan skala hasil (return to scale) apakah meningkat, tetap atau menurun dengan menggunakan data-data kuntitatif.

Analisis produktivitas dengan menggunakan fungsi produksiCobb Douglas dilakukan dengan menggunakan data kuantitas produksi alkohol sebagai outputnya dan jumlah bahan baku tetes sebagai inputnya.Penggunaan jumlah bahan baku tetes sebagai input dilakukan karena proses produksi di Pabrik Spiritus PT XY menggunakan tetes sebagai bahan baku utama untuk menghasilkan alkohol, sehingga tetes merupakan input yang paling penting untuk dapat menjalankan proses produksi.

Untuk pengukuran produktivitas menggunakan fungsi produksi Cobb Douglas, pengukuran dilakukan untuk setiap periode produksi atau setiap 15 hari produksi. Periode produksi yang diterapkan di Pabrik Spiritus PT XY, satu bulan terbagi menjadi dua periode, sehingga dalam satu tahun terdapat 24 periode produksi.Hal ini dilakukan untuk mendapatkan hasil pengukuran yang lebih teliti, mengingat metode ini menggunakan data-data kuantitatif.

\section{TujuanPenelitian}

1. Mengetahui kondisi produktivitas Pabrik Spiritus PT XYZ menggunakan fungsi produksi Cobb-Douglas.

2. Mengetahui Indeks Produktivitas yang dicapai Pabrik spiritus PT XYZ.

\section{TINJAUAN PUSTAKA}

\section{A. Produktivitas}

Produktivitas diartikan sebagai suatu ukuran dimana sumber-sumber yang ada digabungkan dan dipergunakan dengan baik sehingga tercapai hasil-hasil tertentu yang diinginkan(Sinungan,1995). Pada dasarnya produktivitas adalah ukuran yang menunjukkan perbandingan antara keluaran dan masukan, yaitu besar keluaran yang dihasilkan dari setiap masukan yang digunakan (Bain,1982).

$$
\text { Indeks produktivitas }=\frac{\text { output yang dihasilkan }}{\text { input yang dipergunakan }}
$$

Suatu organisasi perusahaan perlu mengetahui pada tingkat produktivitas mana perusahaan itu beroperasi, agar dapat membandingkannya dengan produktivitas standar yang telah ditetapkan manajemen.

Terdapat beberapa manfaat pengukuran produktivitas dalam suatu organisasi perusahaan, antara lain (Gasperz, 1995) :

1. Perusahaan dapat menilai efisiensi konversi sumber dayanya agar dapat meningkatkan produktivitas melalui efisiensi penggunaan sumber daya itu.

2. Perencanaan sumber daya akan menjadi lebih efektif dan efisien melalui pengukuran produktivitas, baik dalam perancanaan jangka pendek maupun jangka panjang.

3. Tujuan ekonomis dan non ekonomis dari perusahaan dapat diorganisasikan kembali, dengan cara memberikan prioritas tertentu dipandang dari sudut produktivitas.

4. Perencanaan target tingkat produktivitas dimasa mendatang dapat dimodifikasi kembali, berdasarkan informasi pengukuran tingkat produktivitas sekarang.

5. Strategi untuk meningkatkan produktivitas perusahaan dapat ditetapkan, berdasarkan tingkat kesenjangan produktivitas yang ada diantara tingkat produktivitas yang direncanakan dengan tingkat produktivitas yang diukur.

6. Pengukuran produktivitas perusahaan akan menjadi informasi yang bermanfaat, dalam membandingkan tingkat produktivitas di antara organisasi perusahaan dalam industri sejenis. Serta bermanfaat pula untuk informasi produktivitas industri pada skala nasional maupun global. 
7. Menciptakan tindakan-tindakan kompetitif berupa upaya-upaya peningkatan produktivitas terus menerus.

8. Pengukuran produktivitas secara terus menerus akan memberikan informasi yang bermanfaat untuk menentukan dan mengevaluasi kecenderungan perkembangan produktivitas perusahaan dari waktu ke waktu.

9. Memberikan informasi dalam mengevaluasi perkembangan dan efektivitas dari perbaikan terus menerus yang dilakukan dalam perusahaan itu.

10. Memberikan motivasi kepada orang-orang untuk secara terus menerus melakukan perbaikan dan juga meningkatkan kepuasan kerja.

\section{B. Pengukuran Produktivitas}

Konsep pengukuran produktivitas telah dikembangkan secara luas dengan berbagai macam analisis yang mendasarinya (Gasperz, 1995). Pada konsep pengukuran produktivitas ini terdapat beberapa tipe pengukuran produktivitas yang dilakukan, yaitu :

1. Produktivitas Parsial.

Produktivitas parsial merupakan metode yang paling umum digunakan. Pengukuran dengan metode ini yaitu mengukur rasio output terhadap salah satu jenis input saja, misalnya produktivitas material adalah rasio antara keluaran dengan jumlah material sebagai masukan.

2. Produktivitas multifaktor

Produktivitas multifaktor merupakan pengukuran produktivitas yang menggunakan rasio keluaran terhadap sejumlah masukan. Pada metode ini dipertimbangkan faktorfaktor yang mendukung dalam pengukuran produktivitas.

Beberapa metode pengukuran produktivitas multifaktor adalah :

1. Produktivitas total

Produktivitas total merupakan rasio dari total keluaran terhadap total masukan

2. Produktivitas faktor total

Produktivitas faktor total merupakan rasio dari keluaran bersih terhadap banyaknya tenaga kerja dan modal yang digunakan.Output pada metode ini merupakan pengurangan antara total pengeluaran dengan barang atau jasa yang digunakan dalam proses produksi ( Ghebrit, 2004). Metode ini diformulasikan sebagai berikut :

$$
\text { Produktivitas faktor total }=\frac{\text { keluaran }(\text { material }+ \text { energi }+ \text { others })}{\text { tenaga } k \text { kerja }+ \text { modal }}
$$

3. Produktivitas dengan metode Objective Matrix (OMAX)

Pengukuran produktivitas dengan metode Objective Matrix merupakan pengukuran multifaktor yang dkembangkan untuk memantau produktivitas di tiap bagian perusahan dengan kriteria produktivitas sesuai dengan keberadaannya.

\section{Fungsi Produksi}

Fungsi produksi adalah fungsi yang menunjukkan hubungan fisik antara tingkat output dan tingkat (kombinasi) input yang digunakan. Secara sistematis dapat dinyatakan sebagai berikut :

$$
\mathrm{Y}=\mathrm{F}\left(\mathrm{X}_{1}, \mathrm{X}_{2}, \mathrm{X}_{3}, \ldots \ldots \mathrm{X}_{\mathrm{n}}\right)
$$

Dimana $\mathrm{Y}$ adalah tingkat output atau produksi dan $\mathrm{X}_{1}, \mathrm{X}_{2}, \mathrm{X}_{3}, \ldots . . \mathrm{X}_{\mathrm{n}}$ adalah input-input yang digunakan atau faktor produksi (Sumarsono, 2007).

Berdasarkan elastisitas produksinya, maka kurva produksi terbagi dalam 3 daerah, yaitu (Boediono, 1995):

1. Daerah dengan elastisitas produksi lebih besar daripada satu (EP>1). Daerah ini disebut daerah yang tidak rasional, karena produsen dianggap tidak rasional apabila tidak menambah input variabel di daerah ini. 
2. Daerah dengan elastisitas produksi antara 0 sampai $1(0<\mathrm{Ep}<1)$. Daerah ini disebut daerah rasional, karena produsen akan terus menambahkan input variabel untuk menaikkan outputnya, sehingga produsen akan dapat mencapai pendapatan maksimum/ produksi optimal.

3. Daerah dengan elastisitas produksi kurang dari nol $(\mathrm{Ep}<0)$. Daerah ini disebut daerah yang tidak rasional, karena produsen dianggap tidak rasional apabila terus menambah inputnya karena akan menurunkan produksi.

\section{PengukuranProduktivitasDenganFungsi Cobb-Douglas}

Fungsi Cobb-Douglas adalah suatu fungsi perpangkatan yang terdiri dari dua variabel atau lebih, dimana variabel yang satu disebut variabel yang dijelaskan $\mathrm{Y}$ (Variabel tidak bebas) dan yang lain disebut variabel yang menjelaskan $\mathrm{X}$ (Variabel bebas). Penyelesaian hubungan antara $\mathrm{Y}$ dan $\mathrm{X}$ biasanya adalah dengan cara regresi dimana variasi Y akan dipengaruhi oleh variasi X( Soekartawi, 1990).

Model pengukuran produktivitas berdasarkan pendekatan fungsi produksi CobbDouglas adalah (Gasperz, 1995) salah satu bentuk fungsi produksi yang paling banyak dipergunakan dalam analisis produktivitas.

Fungsi produksi Cobb-Douglas termasuk bentuk eksponensial yang melibatkan dua / lebih variabel bebas (X) dengan satu variabel tidak bebas (Y). Pada dasarnya model CobbDouglas juga merupakan persamaan regresi non linier yang berupa fungsi perpangkatan.Bentuk modelnya adalah

$$
\mathrm{Y}=\mathrm{A} \mathrm{X}_{1}^{\mathrm{b} 1} \mathrm{X}_{2}^{\mathrm{b} 2} \ldots \ldots \ldots \ldots . \mathrm{X}_{\mathrm{n}}^{\mathrm{bn}} \text {. }
$$

Dimana :

$\mathrm{Y}=$ variabel dependen

$\mathrm{Xn}=$ variabel independen untuk input $\mathrm{n}$

bn $=$ elastisitas produksi pada input $\mathrm{n}$

$\mathrm{n}=$ jumlah variabel independen dimana $\mathrm{n}=1,2,3 \ldots \ldots . . \mathrm{n}$

A $=$ konstanta

Dengan melakukan perubahan ke dalam bentuk logaritma, maka akan diperoleh bentuk linier sebagai berikut :

$$
\ln \mathrm{Y}=\ln \mathrm{A}+\mathrm{b}_{1} \ln \mathrm{X}_{1}+\ldots \ldots \ldots \ldots \ldots+\mathrm{b}_{\mathrm{n}} \ln \mathrm{Xn}
$$

Bentuk umum fungsi produksi Cobb-Douglas dengan satu input, yaitu dengan menggunakan input bahan baku adalah sebagai berikut :

$$
\begin{aligned}
& \mathrm{Y}=\mathrm{AM}^{\alpha} \\
& \frac{d \dddot{Y}}{d M}=A \cdot \alpha(M)^{\alpha-1} \\
& \frac{d^{2} Y}{d M^{2}}=A \cdot \alpha(\alpha-1) M^{\alpha-2}
\end{aligned}
$$

Dimana :

$\mathrm{Y}=$ output

$\mathrm{M}=$ input bahan baku

$\mathrm{A}=$ konstanta

$\alpha=$ elastisitas produksi pada input bahan baku

Pada persamaan tersebut berlaku sifat-sifat :

a. Jika $\alpha=1$, maka fungsi produksi berada pada tahap constan return to scale.

b. Jika $\alpha<1$, maka fungsi produksi berada pada tahap decreasing return to scale..

c. Jika $\alpha>1$, maka fungsi produksi berada pada tahap increasing return to scale. 


\section{E. Menghitung Indeks Produktivitas}

Tujuan menghitung indeks produktivitas adalah untuk mengetahui perkembangan produktivitas pabrik, terjadi peningkatan, tetap, atau penurunan. Perhitungan indeks produktivitas dilakukan dengan dua cara:

1. Dengan membandingkan total nilai indikator pencapaian dengan nilai indikator standar

2. Dengan membandingkan dengan total nilai indikator periode sebelumnya.

Produktivitas memiliki nilai indikator pencapaian 300, yang berasal dari perkalian pencapaian standar ( skor 3) dengan bobot total keseluruhan rasio yaitu 100.

\section{METODOLOGI PENELITIAN}

Metodologi penelitian ini digambarkan pada Diagram Alir Tahapan Penelitian seperti Gambar 1.

\section{PENGUMPULAN DAN PENGOLAHAN DATA}

Untuk melakukan analisis produktivitas dengan menggunakan fungsi produksi CobbDouglas dan Metode Objective Matrix dilakukan pengumpulan dan pengolahan data sebagai berikut :

\section{A. Pengumpulan Dan Pengolahan Data Menggunakan Fungsi Produksi Cobb-Douglas}

Data-data yang diperlukan untuk menghitung produktivitas Pabrik Spiritus Madukismo dengan fungsi produksi Cobb-Douglas adalah data input dan data output produksi yang diambil dari bagian produksi. Data-data tersebut adalah :

\section{B. Data Input}

Input merupakan masukan yang digunakan untuk menghasilkan suatu output. Input yang dipakai oleh Pabrik Spiritus Madukismo untuk memproduksi alkohol adalah jumlah penggunaan bahan baku tetes, dinyatakan dalam satuan Kilogram. Data inputyang dipakai selama periode pengukuran, yaitu 12 bulan yang terbagi 24 periode ( satu periode adalah 15 hari) ditunjukkan pada Tabel 1

Tabel 1. Data Input Penggunaan Bahan Baku Tetes

\begin{tabular}{|c|l|c|l|}
\hline Periode & $\begin{array}{c}\text { Tmput Bahan } \\
\text { Baku Tetes (kg) }\end{array}$ & Periode & $\begin{array}{c}\text { Imput Bahan } \\
\text { Baku Tetes (kg) }\end{array}$ \\
\hline 1 & 1.321 .700 & 13 & 1.110 .254 \\
\hline 2 & 1.579 .775 & 14 & 1.261 .932 \\
\hline 3 & 1.292 .530 & 15 & 1.094 .409 \\
\hline 4 & 761.533 & 16 & 1.024 .772 \\
\hline 5 & 1.011 .812 & 17 & 966.365 \\
\hline 6 & 1.321 .748 & 18 & 857.903 \\
\hline 7 & 1.153 .227 & 19 & 852.570 \\
\hline 8 & 651.192 & 20 & 1.292 .483 \\
\hline 9 & 1.108 .731 & 21 & 1.109 .105 \\
\hline 10 & 1.153 .763 & 22 & 1.137 .513 \\
\hline 11 & 946.176 & 23 & 1.159 .070 \\
\hline 12 & 1.019 .675 & 24 & 1.121 .900 \\
\hline
\end{tabular}

\section{Data Output}

Output merupakan keluaran yang dihasilkan dalam suatu proses produksi sesuai dengan standar-standar tertentu. Output yang dihasilkan di Pabrik Spiritus Madukismo adalah produk alkohol. Alkohol dibagi menjadi dua jenis yaitu alkohol murni dan teknis. Alkohol teknis inilah nanti yang kemudian diolah menjadi spiritus. Output yang digunakan dalam perhitungan ini adalah berupa produk alkohol secara keseluruhan. Jumlah produk alkohol yang dihasilkan oleh Pabrik Spiritus Madukismo selama periode pengukuran yaitu 12 bulan yang terbagi 24 periode ditunjukkan pada Tabel 2. 


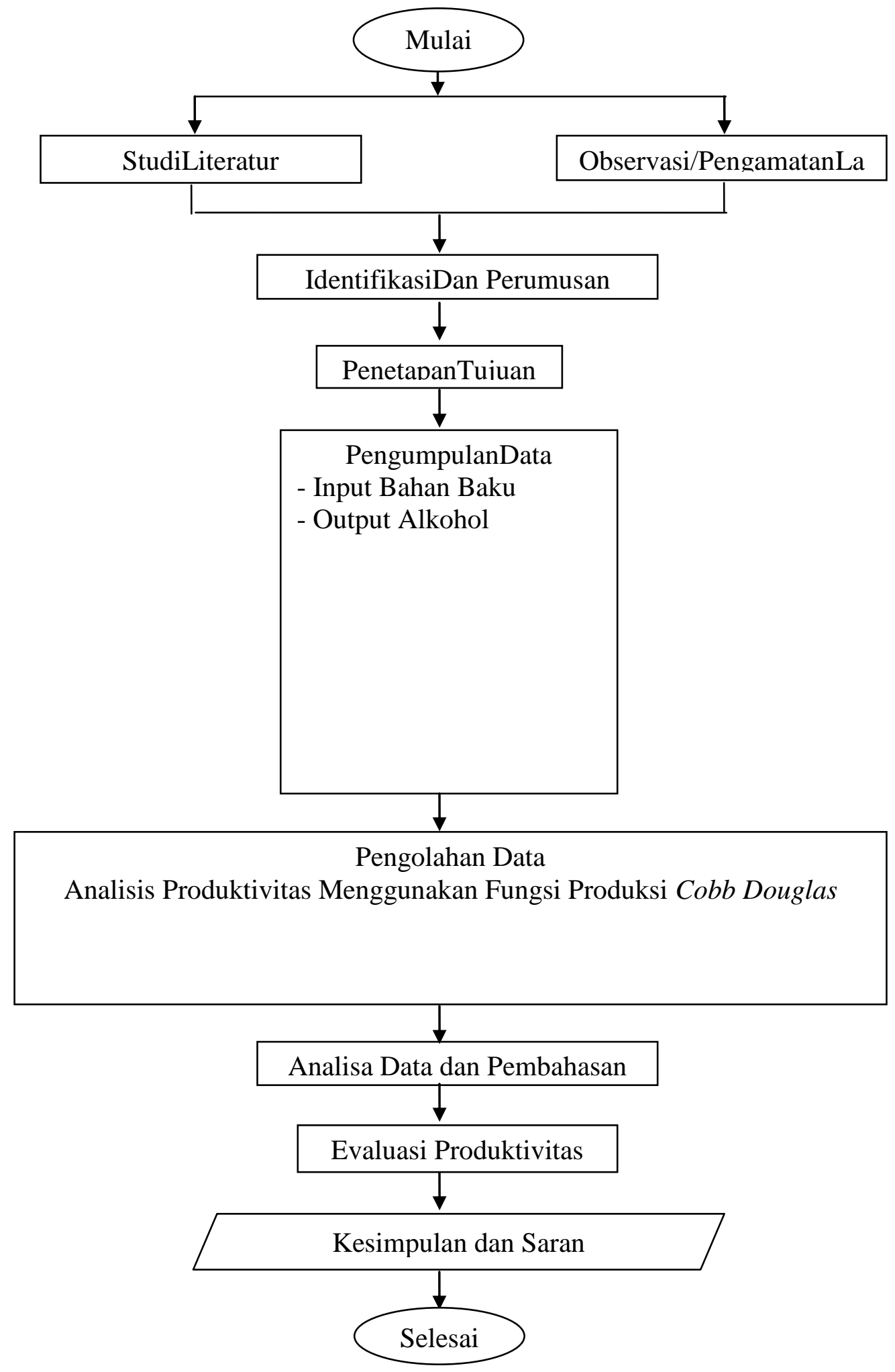

Gambar 1. Diagram Alir Tahapan Penelitian 
Tabel 2. Data Output Produksi Alkohol

\begin{tabular}{|c|c|c|c|}
\hline Periode & $\begin{array}{l}\text { Ouzput Alko ho } 1 \\
\text { (Q) (hiter) }\end{array}$ & Periode & $\begin{array}{l}\text { Oudput Alko ho } 1 \\
\text { (Q) (liter) }\end{array}$ \\
\hline 1 & 411.190 & 13 & 347.500 \\
\hline 2 & 485.200 & 14 & 397.100 \\
\hline 3 & 400.700 & 15 & 347.200 \\
\hline 4 & 253.000 & 16 & 326.200 \\
\hline 5 & 321.900 & 17 & 290.900 \\
\hline 6 & 411.200 & 18 & 274.800 \\
\hline 7 & 367.100 & 19 & 278.900 \\
\hline 8 & 223.200 & 20 & 400.600 \\
\hline 9 & 351.200 & 21 & 349.600 \\
\hline 10 & 351.400 & 22 & 361.700 \\
\hline 11 & 296.700 & 23 & 365.900 \\
\hline 12 & 308.100 & 24 & 363.700 \\
\hline
\end{tabular}

\section{Nilai Logaritma Data Input - Output}

Penggunaan input jumlah bahan baku tetes (M) dan jumlah produksi atau output (Q) selanjutnya akan dipakai untuk analisis produktivitas dengan menggunakan fungsi produksi Cobb-Douglas, dengan mentransformasikan data produksi dan jumlah bahan baku tetes tersebut ke dalam logaritma natural (ln) yang berbilangan dasar e $=2,71828$. Nilai hasil transformasi input dan output dalam bentuk logaritma natural (ln) ditunjukkan dalam Tabel 3.

Tabel 3. Nilai Logaritma Data Input dan Output

\begin{tabular}{|c|c|c|c|c|c|c|c|c|c|}
\hline Periode & $\begin{array}{l}\text { Data Inpout } \\
\text { (M) }\end{array}$ & $\ln M$ & $\begin{array}{l}\text { Data Output } \\
\text { (Q) }\end{array}$ & $\ln Q$ & Periode & $\begin{array}{l}D \text { ata Inpout } \\
\text { (M) }\end{array}$ & $\ln M$ & $\begin{array}{l}\text { Data Output } \\
\text { (Q) }\end{array}$ & $\ln Q$ \\
\hline 1 & 1.321 .700 & 14,09 & 411.190 & 12,93 & 13 & 1.110 .254 & 13,91 & 347.500 & 12,76 \\
\hline 2 & 1.579 .775 & 14,27 & 485.200 & 13,09 & 14 & 1.261 .932 & 14,05 & 397.100 & 12,89 \\
\hline 3 & 1.292 .530 & 14,07 & 400.700 & 12,90 & 15 & 1.094 .409 & 13,91 & 347.200 & 12,76 \\
\hline 4 & $\begin{array}{r}1.292 .530 \\
761.533\end{array}$ & 13,54 & 253.000 & 12,44 & 16 & 1.024 .772 & 13,84 & 326.200 & 12,70 \\
\hline 5 & 1.011 .812 & 13,83 & 321.900 & 12,68 & 17 & 966.365 & 13,78 & 290.900 & 12,58 \\
\hline 6 & 1.321 .748 & 14,09 & 411.200 & 12,93 & 18 & 857.903 & 13,66 & 274.800 & 12,52 \\
\hline 7 & 1.153 .227 & 13,96 & 367.100 & 12,81 & 19 & 852.570 & 13,66 & 278.900 & 12,54 \\
\hline 8 & 651.192 & 13,39 & 223.200 & 12,32 & 20 & 1.292 .483 & 14,07 & 400.600 & 12,90 \\
\hline 9 & 1.108 .731 & 13,92 & 351.200 & 12,77 & 21 & 1.109 .105 & 13,92 & 349.600 & 12,76 \\
\hline 10 & 1.153 .763 & 13,96 & 351.400 & 12,77 & 22 & 1.137 .513 & 13,94 & 361.700 & 12,80 \\
\hline 11 & 946.176 & 13,76 & 296.700 & 12,60 & 23 & 1.159 .070 & 13,96 & 365.900 & 12,81 \\
\hline 12 & 1.019 .675 & 13,84 & 308.100 & 12,64 & 24 & 1.121 .900 & 13,93 & 363.700 & 12,80 \\
\hline
\end{tabular}

\section{E. Pendugaan Parameter Regresi Fungsi Cobb-Douglas}

Selanjutnya nilai dalam Tabel 3 di atas digunakan untuk perhitungan koefisienkoefisien fungsi produksi Cobb-Douglas menggunakan analisis regresi linear logaritmik. Perhitungan pendugaan regresi linear logaritmik untuk nilai logaritma input dan nilai logaritma outputditunjukkan dalam Tabel 4 berikut

Tabel 4. Perhitungan Pendugaan Parameter Regresi Fungsi Produksi Cobb-Douglas

\begin{tabular}{|c|c|c|c|c|c|c|c|c|c|}
\hline Periode & $\operatorname{Ln} Q$ & $\operatorname{LnM}$ & $(\ln Q)(\ln M)$ & $(\ln M)^{2}$ & Periode & $\operatorname{Ln} Q$ & $\operatorname{Ln} M$ & $(\ln Q)(\ln M)$ & $(\ln M)^{2}$ \\
\hline 1 & 12,93 & 14,09 & 182,1837 & 198,5281 & 13 & 12,76 & 13,92 & 177,6192 & 193,7664 \\
\hline 2 & 13,09 & 14,27 & 186,7943 & 203,6329 & 14 & 12,89 & 14,05 & 181,1045 & 197,4025 \\
\hline 3 & 12,90 & 14,07 & 181,5030 & 197,9649 & 15 & 12,76 & 13,91 & 177,4916 & 193,4881 \\
\hline 4 & 12,44 & 13,54 & 168,4376 & 183,3316 & 16 & 12,70 & 13,84 & 175,7680 & 191,5456 \\
\hline 5 & 12,68 & 13,83 & 175,3644 & 191,2689 & 17 & 12,58 & 13,78 & 173,3524 & 189,8884 \\
\hline 6 & 12,93 & 14,09 & 182,1837 & 198,5281 & 18 & 12,52 & 13,66 & 171,0232 & 186,5956 \\
\hline 7 & 12,81 & 13,96 & 178,8276 & 194,8816 & 19 & 12,54 & 13,66 & 171,2964 & 186,5956 \\
\hline 8 & 12,32 & 13,39 & 164,9648 & 179,2921 & 20 & 12,90 & 14,07 & 181,5030 & 197,9649 \\
\hline 9 & 12,77 & 13,92 & 177,7584 & 193,7664 & 21 & 12,76 & 13,92 & 177,6192 & 193,7664 \\
\hline 10 & 12,77 & 13,96 & 178,2692 & 194,8816 & 22 & 12,80 & 13,94 & 178,4320 & 194,3236 \\
\hline 11 & 12,60 & 13,76 & 173,3760 & 189,3376 & 23 & 12,81 & 13,96 & 178,8276 & 194,8816 \\
\hline 12 & 12,64 & 13,84 & 174,9376 & 191,5456 & 24 & 12,80 & 13,93 & 178,3040 & 194,0449 \\
\hline & & & & & Jumlah & 305,7 & 333,36 & 4246,9414 & 4631,2230 \\
\hline
\end{tabular}

\section{F. Analisis Fungsi Cobb-Douglas dengan SPSS 10,0}

Selanjutnya Perhitungan pendugaan regresi linear logaritmik untuk nilai logaritma inputdan nilai logaritma outputditunjukkan dalam Tabel 4 di atas digunakan untuk analisis fungsi Cobb-Douglas dengan menggunakan software SPSS 10,0. Ringkasan analisis menggunakan software SPSS 10,0 ditunjukkan dalam Tabel 5 berikut 


\begin{tabular}{|c|c|c|c|c|}
\hline \multicolumn{5}{|c|}{ Tabel 5. Ringkasan Hasil Perhitungan Komputer Menggunakan SPSS 10.0} \\
\hline Dependent variabel & $\ln \mathrm{Q}$ & $\mathrm{F}(\mathrm{DF}=1 ; 22)$ & $: 1405,456$ & \\
\hline Observations & 24 & $\begin{array}{l}\text { PROB } \\
\text { R-SQUARE }\end{array}$ & $\begin{array}{l}: 0,00 \\
: 0,985\end{array}$ & \\
\hline VARIABEL & $\begin{array}{l}\text { REGRESSION } \\
\text { COEFFICIENT }\end{array}$ & STANDARD ERROR & $\mathrm{T}(\mathrm{DF}=22)$ & PROB \\
\hline $\begin{array}{l}\text { Intercept(Constant) } \\
\text { LnA }\end{array}$ & 0,256 & 0,02225 & 0,769 & 0,450 \\
\hline $\ln M$ & 0,899 & & 37,489 & 0,000 \\
\hline
\end{tabular}

\section{G. Fungsi Produksi Cobb-Douglas :}

Dari hasil software SPSS 10,0 maka akan diperoleh bentuk transformasi fungsi produksi Cobb-Douglas Pabrik Spiritus Madukismo sebagai berikut :
Bentuk linear
$\ln \mathrm{Y}=\ln \mathrm{A}+\mathrm{b}_{1} \ln \mathrm{X}_{1}+\ldots$ ..$+b_{n} \ln X n$
Sehingga
$\ln \mathrm{Q}=0,256+0,899 \ln \mathrm{M}$

Bentuk umum fungsi produksi Cobb-Douglas Pabrik Spiritus Madukismo dengan satu input adalah sebagai berikut :

$\mathrm{Y}=\mathrm{AM}^{\alpha}$

dimana

$$
\begin{aligned}
& \text { Ln } A=0,256 \\
& A=e^{0,256} \\
& A=2,71828^{0,256} \\
& A=1,292
\end{aligned}
$$

sehingga

$$
Q=1,292 M^{0,899}
$$

\section{H. Menghitung Indeks Produktivitas}

Tujuan menghitung indeks produktivitas adalah untuk mengetahui perkembangan produktivitas pabrik, terjadi peningkatan, tetap, atau penurunan. Perhitungan indeks produktivitas dilakukan dengan dua cara:

1. Dengan membandingkan total nilai indikator pencapaian dengan nilai indikator standar

2. Dengan membandingkan dengan total nilai indikator periode sebelumnya.

\begin{tabular}{|c|c|c|c|c|}
\hline Bulan & $\begin{array}{l}\text { Total Nilai } \\
\text { Indikator } \\
\text { Pencapaian }\end{array}$ & $\begin{array}{l}\text { Produktivitas } \\
\text { Standar }\end{array}$ & $\begin{array}{c}\text { Indeks } \\
\text { Produkti vitas } \\
\text { (Dibandingkan } \\
\text { dengan } \\
\text { produktivitas } \\
\text { Standar) } \\
\end{array}$ & $\begin{array}{c}\text { Indeks } \\
\text { Produktivitas } \\
\text { (Dibandingkan } \\
\text { dengan } \\
\text { Periode/bul an } \\
\text { sebelumnya) }\end{array}$ \\
\hline & a & $b$ & $c(\langle a: b) / b) \times 100 \%$ & $d(\%)$ \\
\hline Januari & 506 & 300 & 68,7 & 0 \\
\hline Februari & 296 & 300 & $-1,3$ & -42 \\
\hline Maret & 328 & 300 & 9,3 & 11 \\
\hline April & 298 & 300 & $-0,7$ & -9 \\
\hline Mei & 398 & 300 & 32,7 & 34 \\
\hline Juni & 382 & 300 & 27,3 & -4 \\
\hline Juli & 432 & 300 & 44,0 & 13 \\
\hline Agustus & 340 & 300 & 13,3 & -21 \\
\hline September & 409 & 300 & 36,3 & 20 \\
\hline Oktober & 242 & 300 & $-19,3$ & -41 \\
\hline November & 388 & 300 & 29,3 & 60 \\
\hline Desember & 559 & 300 & 86,3 & 44 \\
\hline Rata-rata & 382 & 300 & 27,2 & 5,4 \\
\hline
\end{tabular}

Produktivitas memiliki nilai indikator pencapaian 300, yang berasal dari perkalian pencapaian standar ( skor 3) dengan bobot total keseluruhan rasio yaitu 100.

Indeks produktivitas Pabrik Spiritus PT. XYZ dapat dilihat pada Tabel 6 berikut :

Tabel 6. Indeks Produktivitas Pabrik Spritus 


\section{ANALISA DAN INTERPRETASI}

\section{A. Menggunakan Fungsi Produksi Cobb Douglas}

Fungsi produksi Cobb-Douglas merupakan persamaan regresi non linier, sehingga untuk memperoleh bentuk liniernya maka harus diubah menjadi bentuk linear logaritmik. Setelah didapat bentuk linearnya, untuk membuktikan bahwa persamaan yang didapat merupakan bentuk linear maka dilakukan pengujian keakuratan data.

\section{B. Keakuratan Data}

Berdasarkan hasil regresi data yang telah ditransformasikan ke dalam bentuk logaritmik natural didapatkan data yang akurat/signifikan dengan keterangan sebagai berikut :

\section{1. $\mathrm{Uji} \mathrm{R}^{2}$}

Uji $\mathrm{R}^{2}$ atau disebut juga dengan koefisien determinasi, merupakan suatu alat analisis yang dapat digunakan untuk mengetahui seberapa besar perubahan/ variasi suatu variabel bisa dijelaskan oleh perubahan/ variasi pada variabel yang lain.

Pada hasil perhitungan dengan menggunakan software SPSS 10.0 didapat nilai koefisien determinasi pada tahun 2010 sebesar 0,985 . Hal ini berarti 98,5\% output produksi alkohol dipengaruhi oleh variabel jumlah bahan baku tetes sedangkan sisanya sebesar 1,5\% (100\%-98,5\%) dipengaruhi oleh sebab-sebab lain.

2. $\mathrm{Uji} \mathrm{F}$

Uji F merupakan uji kebaikan model yang digunakan untuk mengetahui seberapa baik tidaknya suatu variabel independen dalam memprediksi nilai variabel dependen. Hipotesis untuk menguji persamaan regresi adalah :

Ho: konstribusi variabel independen terhadap variabel dependen tidak signifikan

Ha: konstribusi variabel independent signifikan terhadap variabel dependen.

Berdasarkan hasil analisis pada tahun 2010 didapat nilai $\mathrm{F}$ hitung sebesar 1405,456 dengan nilai signifikan $\mathrm{F}$ adalah 0,00 . Jika kita bandingkan dengan $\mathrm{F}$ tabel dengan mencari pada tabel $\mathrm{F}$ dengan v1 adalah 1 dan v2 adalah 22 diperoleh nilai $\mathrm{F}$ tabel sebesar 4,30 Terlihat bahwa nilai $F$ hitung lebih besar daripada $F$ tabel. Dengan perbandingan tersebut atau dengan melihat nilai signifikan yang lebih kecil daripada alpha (5\%), maka kesimpulan yang dapat diambil adalah menolak Ho yang berarti kontribusi variabel independen signifikan dalam memprediksi nilai variabel dependen.

3. Uji t

Hasil analisis regresi yang berupa persamaan regresi dengan masing-masing koefisien perlu diuji untuk menentukan signifikansi koefisien. Uji ini diperlukan untuk menentukan apakah variabel independent yang digunakan signifikan dalam memprediksi nilai variabel dependen. Hipotesis untuk menguji signifikansi koefisien dirumuskan sebagai berikut :

Ho : koefisien konstanta tidak signifikan

Ha : koefisien konstanta signifikan

Sedangkan untuk uji koefisien variabel independen adalah :

Ho : koefisien variabel independent tidak signifikan

Ha : koefisien variabel independen signifikan

\section{Pengambilan keputusan :}

1. Dengan membandingkan nilai $t$ hitung dengan nilai $t$ tabel, jika $t$ hitung $>t$ tabel, maka Ho ditolak.

Berdasarkan hasil analisis didapat nilai koefisien konstanta sebesar 0,256 dengan t hitung sebesar 0,769. Sedangkan koefisien slope output sebesar 0,899 dengan t hitung sebesar 37,489. Nilai t tabel untuk uji ini adalah sebesar 1,72, yang diperoleh dengan alpha $5 \%$ dan df sebesar 22 (n-1). Jika kita bandingkan nilai t hitung koefisien konstanta dengan $\mathrm{t}$ tabel, terlihat bahwa nilai $\mathrm{t}$ hitung lebih kecil daripada $\mathrm{t}$ tabel sedangkan untuk koefisien slope output terlihat bahwa t hitung lebih besar daripada $t$ tabel. 
Keputusan : Berdasarkan t hitung dan $\mathrm{t}$ tabel untuk koefisien konstanta menerima Ho, sedangkan koefisien slope output keputusan yang diambil adalahmenolak Ho. Maka koefisen konstanta tidak signifikan sedangkan koefisen slope output signifikan secara statistik.

2. Berdasarkan probabilitas

Jika nilai probabilitas $>0,05$, maka Ho diterima

Jika nilai probabilitas $<0,05$, maka Ho ditolak

Berdasarkan hasil analisis pada tahun 2010 didapat nilai sig/probabilitas sebesar 0,450 untuk koefisien konstanta dan 0,000 untuk koefisien slope output.

Keputusan : menerima Ho untuk koefisien konstanta karena nilai sig/probabilitas $>0,05$ dan menolak Ho untuk nilai koefisien slope output karena nilai sig/probabilitas $<0,05$. Maka koefisien konstanta tidak signifikan sedangkan koefisien slope output signifikan secara statistik.

\section{Fungsi Produksi Cobb-Douglas}

Berdasarkan pengujian data yang dilakukan, fungsi produksi Cobb-Douglas Pabrik Spiritus Madukismo dalam penelitian ini adalah :

$$
\mathrm{Q} \quad=1,292 \mathrm{M}^{0,899}
$$

Berdasarkan persamaan fungsi produksi Cobb-Douglas tersebut, maka selanjutnya dapat dilakukan beberapa analisa produktivitas Pabrik Spiritus Madukismo sebagai berikut:

1. Efisiensi produksi

Indeks efisiensi produksi dari Pabrik Spiritus Madukismo pada tahun 2010 adalah sebesar koefisien intersep $\delta=1,292$. Hal ini menggambarkan efisiensi penggunaan input bahan baku tetes dalam menghasilkan output alkohol dari sistem produksi adalah sebesar 1,292.

2. Tingkat produksi berdasarkan input yang digunakan Input yang digunakan adalah jumlah penggunaan bahan baku tetes untuk menghasilkan produk alkohol. Obyek yang dikaji adalah bahan baku, dimana bahan baku tetes merupakan bahan utama yang paling banyak jumlahnya. Elastisitas output dari jumlah bahan baku tetes di PS Madukismo pada tahun 2010 sebesar koefisien $\alpha=0,899$. Hal itu berarti bahwa penambahan tingkat penggunaan jumlah bahan baku tetes sebesar $1 \%$ dari tingkat penggunaan pada tahun 2010 akan menghasilkan peningkatan output sebesar $0,899 \%$ (dengan asumsi bahwa semua faktor lain yang mempengaruhi produksi dianggap konstan).

3. Derajat perubahan output apabila semua input variabel berubah dengan proporsi sama besar

Oleh karena besarnya elastisitas output adalah lebih kecil daripada satu, yaitu sebesar 0,899 . Hal itu mengindikasikan bahwa fungsi produksi dari PS Madukismo pada tahun 2010 bercirikan skala hasil menurun (decreasing returns to scale). Artinya bahwa proporsi penambahan faktor produksi (bahan baku tetes) melebihi proporsi penambahan produksi. Atau dapat dikatakan bahwa output (alkohol) bertambah kurang dari proporsi pertambahan input (tetes).

\section{KESIMPULAN DAN SARAN}

\section{A. Kesimpulan}

Berdasarkan hasil penelitian, analisis dan disimpulkan bahwa

1. Kondisi produktivitas Pabrik Spiritus PT XYZpada periode pengukuran yaitu Januari-Desember 2010 menggunakan fungsi produksi Cobb-Douglas Produktivitas Pabrik SpiritusPT. XYZ bercirikan skala hasil menurun (decreasing returns to scale), dengan elastisitas output sebesar 0,899 . 
2. Indeks Produktivitas Pabrik Spiritus PT. XYZ periode pengukuran produktivitas rata-rata adalah sebesar 382 atau $27,2 \%$ diatas produktivitas standar 300. Dan

\section{B. Saran} Meningkat rata-rata 5,4\% tiap bulan.

Sebaiknya Perusahaan bisa menggunakan fungsi produksi Cobb-Douglasdalam melakukan pengukuran produktivitas perusahaan, selain menggunakan metode pengukuran yang selama ini sudah dipakai untuk membuat kebijaksanaan demi peningkatan produktivitas perusahaan di masa mendatang.

Peningkatan produktivitas Pabrik Spiritus PT. XYZ masih bisa ditingkatkan karena elastisitasnya berada pada daerah rasional. Salah satu cara yang bisa dilakukan adalah dengan peningkatan efisiensi tenaga kerja baik jumlah maupun kualitasnya. Hal ini berdasarkan pada hasil analisa produktivitas yang menunjukkan rasio efisiensi tenaga kerja tergolong dalam kriteria buruk.

\section{DAFTAR PUSTAKA}

[1] Bagus I.P., Lianto, Benny., Tjitro, Bambang.,(2002), Analisa Produktivitas Sistem Produksi dengan Metode OMAX di PT. Saman Wood Proceeding,Seminar Nasional Teknik Industri dan Manajemen Produksi, Surabaya

[2] Bain, D. (1995), The Productivity Prescription: the Manager's Guide to Improving Productivity and Profits, McGraw-Hill, New York.

[3] Boediono, (1995), Ekonomi Mikro : Seri Sinopsis Pengantar Ilmu Ekonomi No 1, edisi 2. BPFE. Yogyakarta.

[4] Sumant, David J(1995),Ekonomi Mikro : Seri Sinopsis Pengantar Ilmu Ekonomi No 1, edisi 2. BPFE. Yogyakarta.

[5] Gasperz, V. (1995), Manajemen Produktivitas Total, Strategi Peningkatan Produktivitas Bisnis Global. Gramedia Pustaka Utama. Jakarta.

[6] Gasperz, V. (2002), Production Planning and Inventory Control. Gramedia Pustaka Utama. Jakarta.

[7] Ghebrit,K, (2004), The Impact of Management Practices on Productivity in The Eritrean Fishing Industry, http://upetd.up.ac.za,diakses tanggal 4 Juli 2011

[8] Ngazo, Herman Y.,(2011), Analisa Produktivitas Berdasarkan Pendekatan The American Productivity Center (APC) dan Cobb Douglas Models Studi kasus : PT XYZ Yogyakarta Jurusan Teknik Industri Fakultas Teknik Unversitas Widya Mataram Yogyakarta.

[9] Rigg, James L.,(1987), Productivity By Objective: Result-Oriented Solution to The Productivity Puzzle, Prentice Hall., New York

[10] Rigg, James L.,G.H. Felix, (1983), Production System: Planning, Analysis\&Control, John Wiley \& Sons,Inc., New York

[11] Sinungan, Muchdaryansah, (1995), Produktivitas Apa dan Bagaimana, Bumi Aksara, Jakarta.

[12] Soekartawi, (1990). TeoriEkonomiProduksidenganPokokBahasanAnalisisFungsi Cobb-Douglas. Rajawali Press. Jakarta.

[13] Sumanth, David J., (1984), Productivity Engineering and Management, McGrawHill,Inc.,New York

[14] Sumarsono, S. (2007). Ekonomi Mikro Teori dan Soal Latihan. Graha Ilmu. Yogyakarta.

[15] Suwarni,( 2011). Analisa Pengukuran Kinerja Perusahaan Dengan Konsep Balanced Scorecard Studi Kasus pada PG. Madukismo.Jurusan Teknik Industri Fakultas Teknik Unversitas Widya Mataram Yogyakarta. 
